\title{
Erratum to: Guarantees and Profit-Sharing Contracts in Project Financing
}

\author{
M. Kabir Hassan • Issouf Soumaré
}

Published online: 3 July 2014

(C) Springer Science+Business Media Dordrecht 2014

\section{Erratum to: J Bus Ethics}

\section{DOI 10.1007/s10551-014-2201-0}

The authors of the above mentioned article would like to add the following paragraph:

Acknowledgements M. Kabir Hassan acknowledges financial support from SABIC Chair for Islamic Financial Markets Studies at Al Imam Mohammad ibn Saudi Islamic University (IMSIU), Riyadh, Saudi Arabia. Issouf Soumaré gratefully acknowledges financial support from the Institut de Finance Mathématique of Montréal, the Fonds Québecois de la Recherche sur la Société et la Culture (FQRSC) and the Social Sciences and Humanities Research Council of Canada (SSHRC). We thank seminar participants at Laval University, the 2006 Asian FA/FMA annual meeting, 2006 Academy of Financial Services annual conference and 2008 Financial Management Association Meetings, and National University of Malaysia, 2012 for their helpful comments and suggestions.

The online version of the original article can be found under doi:10.1007/s10551-014-2201-0.

M. Kabir Hassan ( ()

Department of Economics and Finance, University of New

Orleans, New Orleans, LA 70148, USA

e-mail:mhassan@uno.edu

I. Soumaré

Department of Finance \& Insurance, Faculty of Business

Administration, Laval University, Quebec,

QC G1K 7P4, Canada

e-mail: issouf.soumare@fsa.ulaval.ca 